\title{
Obedience and motivation as mechanisms for adherence to medication: a study in obese type 2 diabetic patients
}

This article was published in the following Dove Press journal:

Patient Preference and Adherence

18 October 201।

Number of times this article has been viewed

\author{
Gérard Reach \\ Department of Endocrinology, \\ Diabetes, and Metabolic Diseases, \\ Avicenne Hospital APHP, and EA \\ 34I2, CRNH-IdF, Paris I 3 University, \\ Bobigny, France
}

Objective: To clarify the mechanisms of adherence.

Methods: A cross-sectional, multicenter French study using a self-questionnaire administered by 116 general practitioners to 782 obese type 2 diabetic patients.

Results: The analysis of 670 completed questionnaires revealed a strong association between the adherence to medication and the behavior of fastening the seatbelt when seated in the rear of a car. Multivariate analysis indicated that this behavior was an independent determinant of adherence to medication (odds ratio [OR] 2.3, 95\% confidence interval [CI] 1.4-3.6, $P<0.001$ ) with the same OR as the motivation to adhere to medical prescriptions (OR 2.2, 95\% CI 1.3-3.6, $P=0.003$ ) in a model with good accuracy (area under the receiver operating characteristic curve 0.774). A multiple correspondence analysis suggested that adherence to medication and seatbelt behavior are "homologous" behaviors, with homology between phenomena defined by the fact that they share a common etiology.

Conclusion: Adherence may have two dimensions: passive (obedience, the main determinant of seatbelt behavior) and active (motivation). This conclusion has theoretical and practical implications. Firstly, empowerment through patient education can be defined as a process that replaces the passive mechanism of adherence in patients' minds with an active, conscious choice. Secondly, recognizing these two dimensions may help to establish a tailored patient-physician relationship to prevent nonadherence.

Keywords: adherence, compliance, motivation, obedience, reactance, patience, seatbelt, medication

\section{Introduction}

Adherence to long-term therapies is an important issue in contemporary medicine. Low adherence to prescribed treatments is very common. Typical adherence rates for prescribed medications are about $50 \%$, with a range from $0 \%$ to over $100 \% .{ }^{1}$ Specifically, for diabetes, there is an inverse relationship between adherence to medication and hemoglobin A1c $\left(\mathrm{HbA}_{1 \mathrm{c}}\right){ }^{2,3} \mathrm{~A}$ multivariate analysis has indicated that nonadherence is significantly associated with increased risks for all-cause hospitalization and allcause mortality. ${ }^{4}$ Adherence to a diabetes therapy has been found to be associated with a decrease in healthcare costs, mostly through a decrease in hospitalization. ${ }^{5,6}$ More generally, a World Health Organization report concluded that increasing the effectiveness of adherence interventions may have a far greater impact on the health of the population than any improvement in specific medical treatments.?

Several studies suggest that adherence and nonadherence are general behaviors. For instance, adherers to medication are often compliant with other tasks related to their 
treatment: adherence to bisphosphonates can be predicted by adherence to another medication, for instance, a statin. ${ }^{8}$ Two studies have shown that adherence to bisphosphonates or statins is associated with the use of preventive health services, such as prostate-specific antigen tests, fecal occult blood tests, screening mammography, and influenza and pneumococcal vaccinations. ${ }^{8,9}$ Furthermore, nonsmokers accept a complex treatment more easily ${ }^{10}$ and are more adherent to bisphosphonate therapy. ${ }^{8}$ By contrast, diabetic patients who smoke are less adherent to recommendations concerning blood-glucose monitoring and exercise and skip more medical appointments than nonsmokers. ${ }^{11}$ Similarly, alcohol consumption is a marker of poorer adherence to diabetes self-care behavior. ${ }^{12}$ Berrigan et al, investigating the adherence to recommendations for five health behaviors (physical activity, tobacco use, alcohol consumption, fruit and vegetable consumption, and dietary fat intake), observed that the two extreme patterns, all adherence and all nonadherence, were found in approximately twice the expected proportions. ${ }^{13}$

This study aimed to clarify the mechanisms of adherence to medication. Obese adult type 2 diabetic patients were asked, via their general practitioner (GP), to complete a self-questionnaire assessing adherence to medication and to answer questions addressing their health, their medications, and their motivation to improve their weight, blood pressure, or diabetes control. Specifically, the hypothesis that adherence to medication may reflect an even more general human behavior was tested. Thus, a question on an apparently distinct behavior was included, asking the patients whether they fastened their seatbelt when they were seated in the rear of a car.

\section{Methods}

This cross-sectional, multicenter French study included 116 GPs and 782 patients who agreed to participate. Diabetic patients treated with a single antidiabetic oral agent, older than 18 years, with an $\mathrm{HbA}_{1 \mathrm{c}}$ level $\geq 6.5 \%$, body mass index $\geq 30 \mathrm{~kg} / \mathrm{m}^{2}$, abdominal obesity according to standard criteria, and who were able to understand the recommendations were eligible to participate in the study. Pregnant women, patients with a severe disease, or those participating in another study were excluded. The participants lived in all regions of the country, both rural ( $9 \%$ were farmers) and urban. Each GP provided between one and 11 evaluable questionnaires (median 6.5, quartiles Q1,Q3: 3,9). Before completing the questionnaire, the patients were given a letter informing them that they could voluntarily participate in a research program with the goal of exploring the determinants of adherence to medical recommendations. The questionnaires from 670 patients $(85.7 \%)$ were considered suitable for evaluation.

The full questionnaire is shown in Appendix I. It included the following questions: (i) nine general questions, such as "Do you think that your health is important?" (possible answers: In no way, A little bit, Rather, A lot), "Does the opinion of your family count?" (possible answers: In no way, A little bit, Rather, A lot), "Generally speaking, what do you give priority to?" (possible answers: To the present, To the future), "Are you used to fastening your seatbelt when you sit in the rear of a car?" (possible answers: No, Yes); (ii) a six-item medication adherence questionnaire, ${ }^{14}$ validated in the field of hypertension, that classified patients as nonadherers if they answered positively to at least two questions, such as "This morning, did you forget to take your medication?" (possible answers: No, Yes); (iii) 17 questions on diabetes control, blood pressure, and weight, such as "Are you satisfied with the control of your blood pressure?" (possible answers: In no way, A little bit, Rather, Completely) and "Would you be ready to make efforts to improve your weight?" (possible answers: In no way, A little bit, Rather, A lot); (iv) three questions on the motivation to follow the recommendations of the physician concerning prescribed medication, physical activity, and dietary advice, such as "Are you motivated to follow the recommendations of your physician with regard to the prescribed medication?" (possible answers: Not motivated, Little motivated, Motivated enough, Very motivated); and (v) one question, "What are the main reasons that motivate you to follow the recommendations of your physician?" for which five answers (for instance, the chance to live longer) were proposed.

For questions with four possible answers, data were dichotomized by pooling the two negative answers and the two positive answers. For the three questions concerning motivations for medication, exercise, and diet, patients were considered to be "motivated" if they stated that they were "motivated enough" or "very motivated" and they were considered "not motivated" if they stated that they were "not motivated" or "little motivated" to at least one of the three questions. Patients' $\mathrm{HbA}_{1 \mathrm{c}}$ levels and body mass indexes were obtained from their GPs.

SAS 8.2 software (SAS Institute Inc, Cary, NC) was used for the statistical analysis. For continuous data, the mean, standard deviation, quartiles Q1 and Q3, and median value were calculated. For categorical data, the frequency and percentage of the class level were calculated. Univariate comparisons were performed using Student's $t$-test for continuous data, the Wilcoxon rank-sum test for ordinal 
categorical data, and the chi-square test for nonordinal categorical data. Multivariate logistic regression analysis was used to determine the independent predictors of adherence to medication. A multiple correspondence analysis of the data was also performed. The research protocol was approved by the University Ethics Review Board.

\section{Results}

The median age of the patients was 60 years (range 21-89 years, Q1,Q3: 53,66); 53.7\% were female, 41\% were retired, $12.4 \%$ were current smokers, $65.3 \%$ had hypertension, and $61.6 \%$ had hypercholesterolemia. The median body mass index was 34.1 (Q1,Q3: 31.6,37.6), and the median $\mathrm{HbA}_{1 \mathrm{c}}$ was 7.0\% (Q1,Q3: 6.7,7.7).

As shown in Table 1, 20.1\% of the patients were classified as nonadherers in the adherence questionnaire. This percentage was more than twice as high in patients who declared that they did not fasten their seatbelt compared with those who $\operatorname{did}(31.5 \%$ versus $14.5 \%, P<0.001)$. In total, $32.2 \%$ of the patients declared that they did not usually fasten their seatbelt. This percentage was twice as high for nonadherers compared with adherers $(51.1 \%$ versus $27.5 \%, P<0.001)$. Furthermore, nonadherers more frequently had an uncontrolled $\mathrm{HbA}_{1 \mathrm{c}}$ level ( $>7 \%$ ) than adherers $(74.2 \%$ versus $54.3 \%, P<0.001)$. The same was true when comparing seatbelt nonfasteners with fasteners $(64.8 \%$ versus $55.0 \%, P=0.016)$.
Table 1 shows items of the questionnaire with statistically different distributions of answers when patients were classified as nonadherers or adherers. Statistical differences were exactly the same when the patients were classified as seatbelt nonfasteners or fasteners.

In a multivariate analysis, the following determinants remained associated with adherence to medication: $\mathrm{HbA}_{1 \mathrm{c}} \leq 7 \%$ (odds ratio [OR] 2.7, 95\% confidence interval [CI] 1.6-4.5, $P<0.001$ ), fastening the seatbelt (OR 2.3, 95\% CI 1.4-3.6, $P<0.001$ ), motivated concerning health (OR 2.2, $95 \%$ CI 1.3-3.6, $P=0.003)$, ready to make efforts to improve diabetes (OR 2.0, 95\% CI 1.2-3.4, $P=0.005$ ), declaring that it is good to follow medical prescriptions (OR 1.9, 95\% CI 1.2-3.0, $P=0.012$ ), and knowledge of one's $\mathrm{HbA}_{1 \mathrm{c}}$ level (OR 1.7, 95\% CI 1.1-2.8, $P=0.016$ ). The area under the receiver operating characteristic (ROC) curve describing this model was 0.774 .

A multiple correspondence analysis of the answers shown in Table 1 was then performed (Figure 1). The dots appear to distinguish two nonoverlapping clusters of answers defining adherent and nonadherent behavior. This figure presents four axes, linking the answers to the questions on adherence, seatbelt behavior, motivation, and priority given to the future. The figure confirms the closeness between the "adherence" and "seatbelt" axes, indicating that these behaviors had similar relationships to the patients' other answers, as shown in Table 1.

Table I Questions with significantly different answer distributions between adherers and nonadherers

\begin{tabular}{|c|c|c|c|c|c|c|c|}
\hline & $\begin{array}{l}\text { Whole } \\
\text { population } \\
(n=670)\end{array}$ & $\begin{array}{l}\text { Adherers } \\
(n=535)\end{array}$ & $\begin{array}{l}\text { Nonadherers } \\
(n=135)\end{array}$ & $P$ & $\begin{array}{l}\text { Seatbelt } \\
\text { fasteners } \\
(n=448)\end{array}$ & $\begin{array}{l}\text { Seatbelt } \\
\text { nonfasteners } \\
(n=213)\end{array}$ & $\boldsymbol{P}$ \\
\hline I Seatbelt nonfasteners & 32.2 & 27.5 & 51.1 & $<0.001$ & & & \\
\hline 2 Nonadherers & 20.1 & & & & 14.5 & 31.5 & $<0.001$ \\
\hline 3 Hemoglobin Alc > 7\% & 58.3 & 54.3 & 74.2 & $<0.001$ & 55 & 64.8 & 0.016 \\
\hline 4 Ex-smoker/current smoker & 25.4 & 22.8 & 35.8 & 0.003 & 19.8 & 36.6 & $<0.001$ \\
\hline 5 Does not measure weight & 48.7 & 43.3 & 70.1 & $<0.001$ & 40.5 & 65.2 & $<0.001$ \\
\hline 6 Not motivated & 46.9 & 40.9 & 70.4 & $<0.001$ & 40.6 & 59.5 & $<0.001$ \\
\hline 7 Priority to the future: no & 60.6 & 58.3 & 70 & 0.013 & 58.1 & 65.6 & 0.065 \\
\hline $\begin{array}{l}8 \text { Not ready to make efforts } \\
\text { to improve diabetes }\end{array}$ & 25.6 & 19.8 & 48.1 & $<0.001$ & 20.7 & 35.5 & $<0.001$ \\
\hline 9 Recommendations too strict & 18.1 & 14.4 & 32.6 & $<0.001$ & 13.8 & 26.7 & $<0.001$ \\
\hline I0 Not interested in changing lifestyle & 8.4 & 6.4 & 16.3 & $<0.001$ & 5.8 & 13.6 & $<0.001$ \\
\hline II Not a priority & 8.5 & 6.2 & 17.8 & $<0.001$ & 6.3 & 13.1 & 0.004 \\
\hline 12 No time & 19.9 & 17 & 31.1 & $<0.001$ & 16.7 & 26.2 & 0.004 \\
\hline 13 Your health depends on you: no & 21 & 17.5 & 35.1 & $<0.001$ & 17.9 & 27.3 & 0.006 \\
\hline I4 Your health is very important: no & 26.4 & 23 & 39.7 & $<0.001$ & 22.2 & 34.7 & $<0.001$ \\
\hline $\begin{array}{l}15 \text { The opinion of your family is very } \\
\text { important: no }\end{array}$ & 64.4 & 62.2 & 73.3 & 0.016 & 59.9 & 73.6 & $<0.001$ \\
\hline $\begin{array}{l}16 \text { Following medical recommendations } \\
\text { is very good: no }\end{array}$ & 27.6 & 22.2 & 48.9 & $<0.001$ & 23.9 & 35.1 & 0.002 \\
\hline
\end{tabular}

Note: It presents the percentages of answers in the whole population (left column), the percentages observed in patients classified as adherers and nonadherers, and the percentages of patients who declared that they fastened their seatbelt when they were seated in the rear of a car and those who did not make this declaration. 


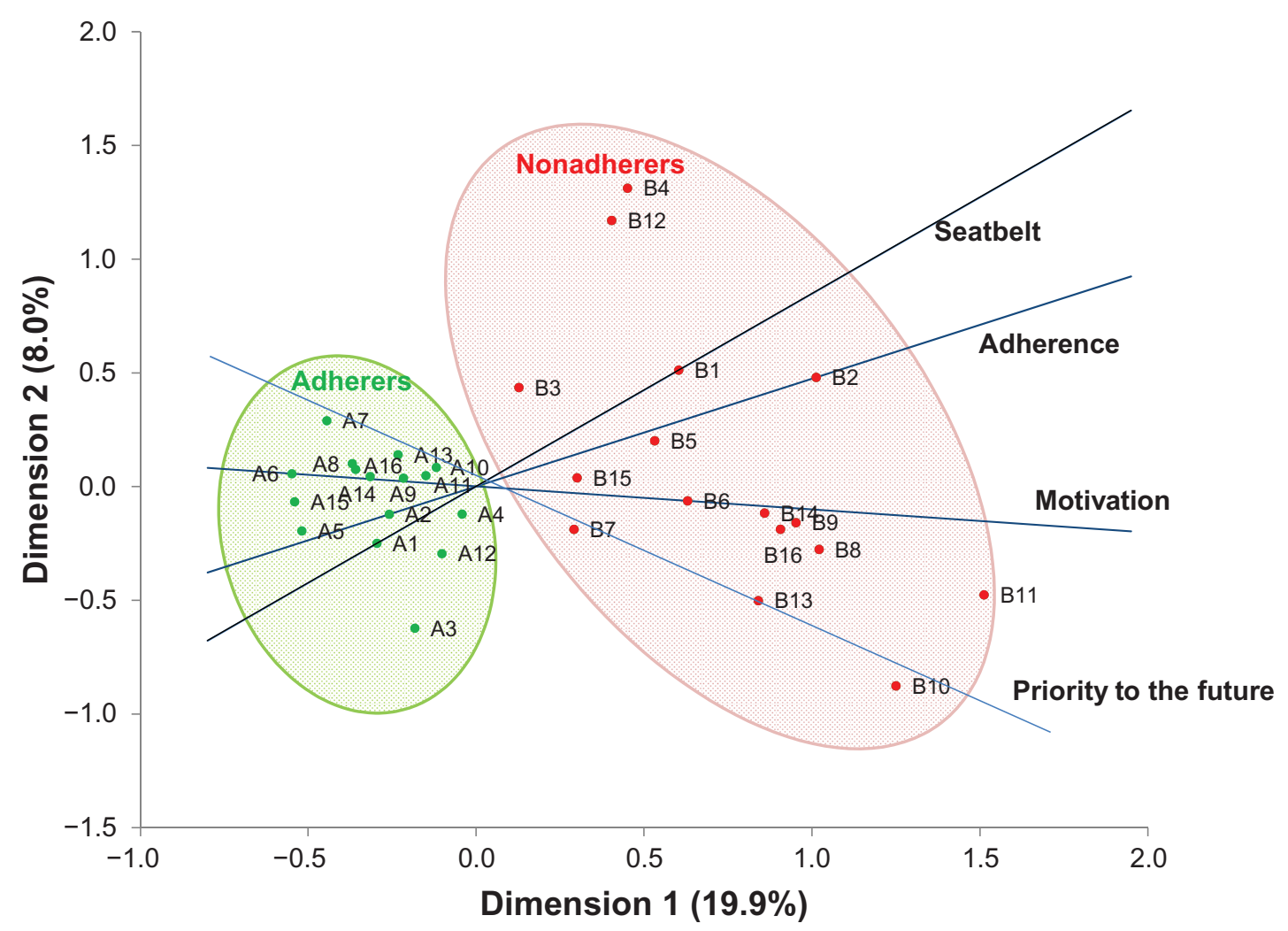

Figure I Multiple correspondence analysis. AI, seatbelt fasteners; $\mathrm{BI}$, seatbelt nonfasteners; $\mathrm{A} 2$, adherers; $\mathrm{B} 2, \mathrm{nonadherers;} \mathrm{A} 3, \mathrm{Hb} \mathrm{I}_{\mathrm{lc}} \leq 7 \%$; $\mathrm{B} 3, \mathrm{Hb} \mathrm{A}_{\mathrm{Ic}}>7 \%$; $\mathrm{A} 4$, nonsmoker; B4, ex-smoker/current smoker; A5, follows weight on a regular basis; B5, does not follow weight; A6, motivated; B6, not motivated; $A 7$, priority to the future: yes; B7, priority to the future: no; A8, ready to make efforts to improve diabetes control; B8, not ready to make efforts to improve diabetes control; $A 9$, recommendations are too strict: disagree; $\mathrm{B}$, recommendations are too strict: agree; AI0, not interested in changing lifestyle: disagree; $\mathrm{BI} 0$, not interested in changing lifestyle: agree; AII, not a priority: disagree; BII, not a priority: agree; AI2, have no time: disagree; BI2, have no time: agree; $\mathrm{AI}$, your health depends on you: agree; $\mathrm{B}$ 3, your health depends on you: disagree; $\mathrm{AI} 4$, your health is very important: agree; $\mathrm{BI} 4$, your health is very important: disagree; $\mathrm{AI}$, the opinion of your family is very important: agree; $\mathrm{BI} 5$, the opinion of your family is very important: disagree; AI6, following doctor's recommendations is very good: agree; BI6, following doctor's recommendations is very good: disagree.

\section{Discussion}

In this study, an unexpected strong association was observed between the adherence to medication and seatbelt fastening when seated in the rear of a car: fastening the seatbelt was found to be a highly significant determinant (OR 2.3, 95\% CI 1.4-3.6, $P<0.001)$ of adherence to medication by multivariate analysis in a model with good accuracy (area under the ROC curve 0.774), with the same OR as the motivation to adhere to medical prescriptions (OR 2.2, 95\% CI 1.3-3.6, $P=0.003$ ). Furthermore, the same pattern of answers to questions on feelings concerning health and treatment and recommendations provided by the GPs was observed when patients were classified as adherers or nonadherers and as seatbelt fasteners or nonfasteners. This striking similarity between apparently distinct behaviors, illustrated by the closeness of the adherence and seatbelt axes in the multiple correspondence analysis (Figure 1), suggests that the adherence to medication, on the one hand, and the fastening of the seatbelt in the rear of a car, on the other, represent "homologous" (not only analogous) behaviors, with homology between the phenomena defined by the fact that they share a common etiology, as explained by Wise and Bozarth: ${ }^{15}$

"In biology, there are examples of superficially similar behaviors or organs that have evolved independently for these "analogous" behaviors or organs look similar, but one cannot draw further conclusion from their similarity. In each case, the analogous details are striking, but there is no commonality of origin, and thus no necessary commonality of mechanism. By contrast, "homologous" organs or behaviors derive from common ancestral origin and, in biology, from common embryonic tissue, whereas analogies do not. Here knowledge of one of a set of homologous organs or behaviors almost necessarily has some degree of heuristic value for the study of the others, even if the organs or behaviors are superficially dissimilar." (Copyright (C) 1987 by the American Psychological Association. Reproduced with permission.)

In other words, discovering a homology between phenomena has a heuristic value because, as stated by Elster, ${ }^{16}$ in the case 
of homologous phenomena, their definition becomes ipso facto inseparable from their explanation.

Thus, understanding why people fasten their seatbelt in the rear of a car may present a clue to the mental mechanisms behind adherence to medication. Langlie ${ }^{17}$ and Williams and Wechsler ${ }^{18}$ observed an association between seatbelt use and the practices of medical check-ups, dental care, immunizations, miscellaneous medical examinations, exercise, and diet. Here, seatbelt use was seen as another health behavior intended to indirectly protect physical well-being. ${ }^{17}$ However, seatbelt behavior may have another meaning. A recent study in Malaysia investigated various factors associated with the behavior of not wearing a rear seatbelt. The experience of being stopped by an enforcement officer yielded the highest OR, followed by factors such as self-consciousness, attitude, knowledge, age, and the perception of being caught by an enforcement officer. ${ }^{19}$ Another study in the Midwest United State ${ }^{20}$ showed that drivers from secondary seatbelt legislation states, where drivers are ticketed only when there is another citable traffic offense, wore their seatbelts significantly less often. This finding reinforces the idea that obedience to the law is the primary cause of this behavior rather than the real wish to protect oneself. On the contrary, some people may refuse to fasten their seatbelt as a typical manifestation of reactance, ${ }^{21}$ defined as a defensive reaction to social pressure that results in rejection of the norm and movement in a negative direction. ${ }^{22}$

Therefore, if there is, as indicated in this study, a "homology" between behavior relating to seatbelt fastening and adherence to medication, we suggest that obedience may also represent a mechanism of patient adherence. Indeed, agreeing that it is good to follow the doctor's prescription was also an independent determinant of adherence to medication in the multivariate analysis of this study. In contrast, reactance has been proposed as a cause of nonadherence to medication. ${ }^{23}$

Interestingly, in this study, the axis linking the answers concerning smoking (dots A4-B4 on Figure 1) was closer to the "seatbelt" axis than to the "motivation" axis, similarly suggesting that nonsmoking behavior may involve a dimension of obedience. On the other hand, the "motivation" and "priority given to the future" axes seemed close in Figure 1. These data are consistent with the role of "patience" in motivation concerning health behaviors, ${ }^{24,25}$ with patience defined as the ability to prioritize the future, preferring a larger, longterm reward (for instance, the beneficial health improvement of tobacco abstinence) rather than a smaller, short-term one (in this example, the pleasure of smoking a cigarette). These speculations call for further investigation.
Dots representing the answers characterizing adherence in Figure 1 clustered in a tight area. It is tempting to hypothesize that patients giving answers that express this "adherent typology" represent the "healthy adherers" who adhere to any recommendation, and this general behavior can explain the puzzling lower mortality rate of patients adhering to a placebo in clinical trials. ${ }^{26}$ Inversely, nonadherence is very frequent in teenagers ${ }^{27}$ and may simply represent one of the manifestations of disobedience that is a normal characteristic of this period of life, together with teenagers' difficulty projecting themselves in the future. ${ }^{28}$ In an even more speculative mode, in the same way that the patience of individuals that leads to adherence ${ }^{24}$ may be, in part, genetically determined ${ }^{29}$ and only fully developed in adulthood ${ }^{30}$ (which may explain why adherence improves with age), ${ }^{13,31-37}$ similar hypotheses may be proposed for obedience.

This study has three limitations. First, there was the unavoidable potential bias because the question concerning seatbelt behavior was asked in the framework of a health questionnaire. Second, this study relied only on the answers to a self-reported questionnaire. Third, it is a cross-sectional study, with the general limitations of such investigations. For instance, both adherence and seatbelt fastening were selfreported. There might be differences between this subjective view and respondents' actual behaviors. It is difficult to determine whether the sample was representative of the population of patients managed by GPs or was a biased sample. Furthermore, the median age of the population was 60 years. Younger people may be more prone to fasten their seatbelt because they were asked from childhood to follow this recommendation. In this framework, we did not observe the association (described in some studies, ${ }^{13,31-37}$ but not all studies ${ }^{38,39}$ ) between age and adherence to medication ( $P=0.34$, no significance), possibly because $75 \%$ of our population was older than 53 years. Further studies are needed to construct and validate a questionnaire to assess obedience in an attempt to evaluate its implications for adherence or nonadherence to medical prescriptions.

\section{Conclusion}

These data suggest that some individuals might adhere to medical prescriptions not because they are motivated to do so but simply because, in general, they agree to conform to rules such as fastening their seatbelt when seated in the rear of a car. Others may have both reasons for being adherent. We therefore propose a typological model of adherence to medication (and possibly of adherence in general) with two components: active (motivation) and passive (obedience). 
This model is consistent with the typological distinction between "critical" and "traditional" adherers proposed by Bader et al for people living with human immunodeficiency virus/acquired immune deficiency syndrome, in which traditional ("unquestioning") adherers have the ability and willingness to follow a therapeutic regimen exactly as prescribed by a medical authority, based on a traditional, asymmetric doctor-patient relationship (paternalistic model). Among "traditional" adherers, Bader et al described a subtype of "faithful" patients who are "obedient and yield readily in a subservient way to doctors' orders." ${ }^{\prime 0}$ This attitude may reflect a more general behavior.

Proposing room for obedience in patient behavior may seem provocative because the switch from the word "compliance" to "adherence," as a means to avoid a connotation that may seem to be in contradiction to the autonomy of the patient, has been presented as a paradigm shift in the understanding of the concept. ${ }^{41}$ The French word used to describe compliance with medical recommendations is "observance." This word originally had a religious meaning: "observance de la règle," obedience to the rule. This is why the word "adhésion," the translation of the English word adherence, is currently preferred. We suggest that these semantic moves might represent a denial of a reality: as shown, adherence to medication might involve a dimension of obedience in some patients.

Practically, a typological description of adherence, with its two components, motivation and obedience, may help to establish tailored patient-physician relationships able to prevent nonadherence. If nonadherence is the consequence of an inability to prioritize the future while patients manage a chronic disease, it may be helpful to stress the short-term advantages of long-term therapies..$^{24,42}$ If patients' behaviors are caused by an innate tendency toward disobedience, a way to reduce the risk of nonadherence would be to avoid presenting the medical prescription in an authoritative way that would lead to reactance. ${ }^{43}$

From a more theoretical point of view, leaving room for obedience in the mental mechanisms leading to adherence should not be seen as a breach in the concept of patient autonomy but rather as the recognition of the complexity of what is at stake in the patient-physician relationship. Specifically, "empowerment" through patient education ${ }^{44}$ can be understood as a process that replaces obedience-driven actions with motivated choices. This conclusion may provide insight into the very meaning of the word "patient" in the framework of this definition. If adherence has two dimensions, active and (as suggested in this study) passive, empowerment would lead the "patient" to become an "agent," recalling the classical distinction given by Descartes in Passions of the Soul: 45 a patient is a subject to whom events happen, whereas an agent is a subject who brings about that they happen:

"To start with, anything that happens is generally labeled by philosophers as a "passion" with regard to the subject to which it happens and an "action" with regard to whatever brings it about that it happens. Thus, although the agent and patient - the maker and the undergoer - are often quite different, an action and passion are always a single thing that has these two names because of the two different subjects to which it may be related."

\section{Acknowledgments}

This study was sponsored by Sanofi-Aventis. The author is grateful to the physicians who participated in the study, to Marmar Kabir Ahmadi and Christian Kempf who performed the statistical analysis, and to Professor Sadek Beloucif for fruitful discussions.

\section{Disclosure}

The author reports no conflicts of interest in this work.

\section{References}

1. Haynes RB, Ackloo E, Sahota N, McDonald HP, Yao X. Interventions for enhancing medication adherence. Cochrane Database Syst Rev. 2008;2:CD000011.

2. Lawrence DB, Ragucci KR, Long LB, Parris BS, Helfer LA. Relationship of oral antihyperglycemic (sulfonylurea or metformin) medication adherence and hemoglobin A1c goal attainment for HMO patients enrolled in a diabetes disease management program. J Manag Care Pharm. 2006;12(6):466-471.

3. Rozenfeld Y, Hunt JS, Plauschinat C, Wong KS. Oral antidiabetic medication adherence and glycemic control in managed care. Am J Manag Care. 2008;14(2):71-75.

4. Ho PM, Rumsfeld JS, Masoudi FA, et al. Effect of medication nonadherence on hospitalization and mortality among patients with diabetes mellitus. Arch Intern Med. 2006;166(17):1836-1841.

5. Lee WC, Balu S, Cobden D, Joshi AV, Pashos CL. Prevalence and economic consequences of medication adherence in diabetes: a systematic literature review. Manag Care Interface. 2006;19(7):31-41.

6. Sokol MC, McGuigan KA, Verbrugge RR, Epstein RS. Impact of medication adherence on hospitalization risk and healthcare cost. Med Care. 2005;43(6):521-530.

7. Sabato E, editor. Adherence to Long Term Therapies - Evidence for Action. Geneva: World Health Organization; 2003.

8. Curtis JR, Xi J, Westfall AO, et al. Improving the prediction of medication compliance: the example of bisphosphonates for osteoporosis. Med Care. 2009;47(3):334-341.

9. Brookhart MA, PatrickAR, Dormuth C, et al. Adherence to lipid-lowering therapy and the use of preventive health services: an investigation of the healthy user effect. Am J Epidemiol. 2007;166(3):348-354.

10. Perros P, Deary IJ, Frier BM. Factors influencing preference of insulin regimen in people with type 1 (insulin-dependent) diabetes. Diabetes Res Clin Pract. 1998;39(1):23-29.

11. Solberg LI, Desai JR, O'Connor PJ, Bishop DB, Devlin HM. Diabetic patients who smoke: are they different? Ann Fam Med. 2004;2(1): 26-32. 
12. Ahmed AT, Karter AJ, Liu J. Alcohol consumption is inversely associated with adherence to diabetes self-care behaviors. Diabet Med. 2006;23(7):795-802

13. Berrigan D, Dodd K, Troiano RP, Krebs-Smith SM, Barbash RB. Patterns of health behavior in US adults. Prev Med. 2003;36(5):615-623.

14. Girerd X, Hanon O, Anagnostopoulos K, Ciupek C, Mourad JJ, Consoli S. Evaluation de 1'observance du traitement antihypertenseur par un questionnaire: mise au point et utilisation dans un service spécialisé. [Assessment of antihypertensive compliance using a self-administered questionnaire: development and use in a hypertension clinic]. Presse Med. 2001;30(21):1044-1048. (French).

15. Wise RA, Bozarth MA. A psychomotor stimulant theory of addiction. Psychol Rev. 1987;94(4):469-492.

16. Elster J. Strong Feelings, Emotions, Addiction and Human Behavior (Jean Nicod Lectures). Cambridge, MA: MIT Press; 2000.

17. Langlie JK. Interrelationships among preventive health behaviors: a test of competing hypotheses. Public Health Rep. 1979;94(3):216-225.

18. Williams AF, Wechsler H. Interrelationship of preventive actions in health and other areas. Health Serv Rep. 1972;87(10):969-976.

19. Mohamed N, Mohd Yusoff MF, Isah N, Othman I, Syed Rahim SA, Paiman N. Analysis of factors associated with seatbelt wearing among rear passengers in Malaysia. Int J Inj Contr Saf Promot. 2011;18(1): $3-10$.

20. Gillespie GL, Al-Natour A, Marcum M, Sheehan H. The prevalence of seatbelt use among pediatric hospital workers. $A A O H N J .2010 ; 58(11)$ : 483-486.

21. Streff FM, Geller ES. Strategies for motivating safety belt use: the application of applied behavior analysis. Health Educ Res. 1986;1(1): 47-59.

22. Brehm JW. A Theory of Psychological Reactance. New York: Academic Press; 1966.

23. Fogarty JS. Reactance theory and patient noncompliance. Soc Sci Med. 1997;45(8):1277-1288.

24. Reach G. A novel conceptual framework for understanding adherence to long term therapies. Patient Prefer Adherence. 2008;2:7-19.

25. Reach G, Michault A, Bihan H, Paulino C, Cohen R, Le Clésiau H. Patients' impatience is an independent determinant of poor diabetes control. Diabetes Metab. May 6, 2011. [Epub ahead of print.]

26. Simpson SH, Eurich DT, Majumdar SR, et al. A meta-analysis of the association between adherence to drug therapy and mortality. BMJ. 2006;333(7557):15.

27. Morris AD, Boyle DI, McMahon AD, Greene SA, MacDonald TM, Newton RW. Adherence to insulin treatment, glycaemic control, and ketoacidosis in insulin-dependent diabetes mellitus. The DARTS/ MEMO Collaboration. Diabetes Audit and Research in Tayside Scotland. Medicines Monitoring Unit. Lancet. 1997;350(9090): 1505-1510.

28. Frederick S. Time preference and identity. In: Loewenstein G, Read D, Baumeister RF, editors. Time and Decision: Economic and Psychological Perspectives on Intertemporal Choice. New York: Russel Sage Foundation; 2003:89-113.

29. Reach $\mathrm{G}$. Is there an impatience genotype leading to non-adherence to long term therapies? Diabetologia. 2010;53(8):1562-1567.
30. Christakou A, Brammer M, Rubia K. Maturation of limbic corticostriatal activation and connectivity associated with developmental changes in temporal discounting. Neuroimage. 2011;54(2):1344-1354.

31. Briesacher BA, Andrade SE, Fouayzi H, Chan KA. Comparison of drug adherence rates among patients with seven different medical conditions. Pharmacotherapy. 2008;28(4):437-443.

32. Lee R, Taira DA. Adherence to oral hypoglycemic agents in Hawaii. Prev Chronic Dis. 2005;2(2):A09.

33. Yang Y, Thumula V, Pace PF, Banahan BF 3rd, Wilkin NE, Lobb WB. High-risk diabetic patients in Medicare Part D programs: are they getting the recommended ACEI/ARB therapy? J Gen Intern Med. 2010;25(4): 298-304.

34. Zhu B, Zhao Z, McCollam P, et al. Factors associated with clopidogrel use, adherence, and persistence in patients with acute coronary syndromes undergoing percutaneous coronary intervention. Curr Med Res Opin. 2011;27(3):633-641.

35. Park DC, Hertzog C, Leventhal H, et al. Medication adherence in rheumatoid arthritis patients: older is wiser. J Am Geriatr Soc. 1999;47(2): $172-183$.

36. Netelenbos JC, Geusens PP, Ypma G, Buijs SJ. Adherence and profile of non-persistence in patients treated for osteoporosis - a large-scale, long-term retrospective study in The Netherlands. Osteoporos Int. 2011; 22(5):1537-1546.

37. Asghari S, Courteau J, Drouin C, et al. Adherence to vascular protection drugs in diabetic patients in Quebec: a population-based analysis. Diab Vasc Dis Res. 2010;7(2):167-171.

38. Jansà $\mathrm{M}$, Hernández $\mathrm{C}$, Vidal $\mathrm{M}$, et al. Multidimensional analysis of treatment adherence in patients with multiple chronic conditions. A cross-sectional study in a tertiary hospital. Patient Educ Couns. 2010; 81(2):161-168.

39. Lutfey KE, Ketcham JD. Patient and provider assessments of adherence and the sources of disparities: evidence from diabetes care. Health Serv Res. 2005;40(6 Pt 1):1803-1817.

40. Bader A, Kremer H, Erlich-Trungenberger I, et al. An adherence typology: coping, quality of life, and physical symptoms of people living with HIV/AIDS and their adherence to antiretroviral treatment. Med Sci Monit. 2006;12(12):CR493-CR500.

41. Lutfey KE, Wishner WJ. Beyond “compliance” is "adherence.” Improving the prospect of diabetes care. Diabetes Care. 1999;22(4):635-639.

42. Reach G. Obstacles to patient education in chronic diseases: a transtheoretical analysis. Patient Educ Couns. 2009;77(2):192-196.

43. Fogarty JS, Youngs GA Jr. Psychological reactance as a factor in patient noncompliance with medication taking: a field experiment. J Appl Soc Psychol. 2000;30(11):2365-2391

44. Funnell MM, Anderson RM, Arnold MS, et al. Empowerment: an idea whose time has come in diabetes education. Diabetes Educ. 1991;17(1): $37-41$.

45. Descartes R. [Passions de l'Ame] (1649), Passions of the Soul, In: Some Texts in Modern Philosophy. Available from: http://www.earlymoderntexts.com/pdfbits/despass1.pdf. Accessed October 4, 2011. 


\section{Appendix I}

The questionnaire

Your health in general

1. Physically, how do you feel?

In very good health In rather good health In poor health In very poor health

2. What do you think that your health generally depends on?

You Other people Chance

3. Do you think that your health is important?

In no way A little bit Rather A lot

4. Does the opinion of your family count?
In no way
A little bit
Rather
A lot

5. Do you think that following the recommendations of your physician is good for you?

In no way A little bit Rather A lot

6. Do you smoke?

No Yes I stopped

7. Generally speaking, what do you give priority to?

To the present To the future

8. Are you used to fastening your seatbelt when you sit in the rear of a car?

No Yes

9. Do you weigh yourself on a regular basis?

No Yes

Your medication (from reference ${ }^{13}$ )

1. This morning, did you forget to take your medication?

No Yes

2. Since the last consultation, did you run out of medication?

No Yes

3. Do you sometimes delay taking your treatment with regard to the usual hour?

No Yes

4. Do you sometimes omit your treatment because, on some days, you forget?

No Yes

5. Do you sometimes omit your treatment because, on some days, you have the feeling that it does more harm than good?

No Yes

6. Do you think that you have too many tablets to take?

No Yes

\section{Your diabetes}

1. What is your last $\mathrm{HbA}_{1 \mathrm{c}}$ level?

$\%$ I do not know

2. Are you satisfied with the control of your diabetes?

In no way A little bit Rather Completely

3. Would you like to improve the control of your diabetes?

In no way A little bit Rather A lot

4. Would you be ready to make efforts to improve the control of your diabetes?

In no way A little bit Rather A lot

Your blood pressure

1. What is your blood pressure? $\mathrm{mmHg} \quad$ I do not know 
2. Are you satisfied with the control of your blood pressure?
In no way
A little bit
Rather
Completely

3. Would you like to improve the control of your blood pressure?
In no way
A little bit
Enough
A lot

4. Would you be ready to make efforts to improve the control of your blood pressure?
In no way
A little bit
Enough
A lot

\section{Your weight}

1. What is your weight?
$\mathrm{k}$
$\mathrm{kg}$
I do not know

2. What is your waist measurement?

$$
\mathrm{cm} \quad \text { I do not know }
$$

3. Are you satisfied with your weight?
In no way
A little bit
Rather
Completely

4. Are you satisfied with your waist measurement?
In no way
A little bit
Rather
Completely

5. Would you like to improve your weight?
In no way
A little bit
Enough
A lot

6. Would you be ready to make efforts to improve your weight?
In no way
A little bit
Enough
A lot

7. What weight would you like to have?

$\mathrm{kg} \quad$ I do not know

8. How many centimeters of waist measurement would you like to lose?

cm I do not know

9. Do you feel hampered in your daily activities because of your weight or your stomach?
In no way
A little bit
Enough
A lot

\section{Your motivation}

1. Are you motivated to follow the recommendations of your physician?

a. With regard to the prescribed medication

$$
\text { Not motivated Little motivated Motivated enough Very motivated }
$$

b. With regard to the practice of a physical activity

Not motivated Little motivated Motivated enough Very motivated

c. With regard to the dietary advice
Not motivated
Little motivated
Motivated enough
Very motivated

2. What are the main reasons that motivate you to follow the recommendations of your physician (several answers are possible):

Feel at ease in my clothes, feel more attractive, be able to buy clothes that I want, to have more energy, to be more active Move better, feel better

Better control of my diabetes, my blood pressure, my cholesterol, and my risk factors for heart disease

The chance to live longer

I trust my doctor

Patient Preference and Adherence

\section{Publish your work in this journal}

Patient Preference and Adherence is an international, peer-reviewed, open access journal focusing on the growing importance of patient preference and adherence throughout the therapeutic continuum. Patient satisfaction, acceptability, quality of life, compliance, persistence and their role in developing new therapeutic modalities and compounds to

optimize clinical outcomes for existing disease states are major areas of interest. This journal has been accepted for indexing on PubMed Central.

The manuscript management system is completely online and includes a very quick and fair peer-review system. Visit http://www.dovepress.com/ testimonials.php to read real quotes from published authors. 